\title{
Energy Caps: Alternative Climate Policy Instruments for China?
}

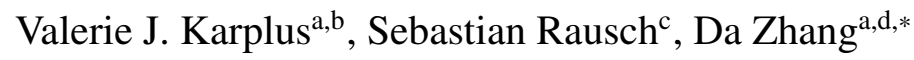 \\ ${ }^{a}$ MIT-Tsinghua China Energy and Climate Project, Tsinghua University, Beijing, China \\ ${ }^{b}$ Sloan School of Management, Massachusetts Institute of Technology, Cambridge, U.S. \\ ${ }^{c}$ Department of Management, Technology and Economics, ETH Zurich, Zurich, Switzerland \\ ${ }^{d}$ Joint Program of the Science and Policy of Global Change, Massachusetts Institute of Technology, Cambridge, U.S.
}

\begin{abstract}
Decoupling fossil energy demand from economic growth is crucial for China's sustainable development, especially for addressing severe local air pollution and global climate change. An absolute cap on coal or fossil fuel consumption has been proposed as a means to support the country's energy and climate policy objectives. We evaluate potential energy cap designs that differ in terms of target fuel, point of control, and national versus regional allowance trading using a global numerical general equilibrium model that separately represents 30 provinces in China. First, we simulate a coal cap and find that relative to a cap on all fossil fuels, it is significantly more costly and results in high localized welfare losses. Second, we compare fossil energy cap designs and find that a national cap on downstream fossil energy use with allowance trading across provinces is the most cost effective. Third, we find that a national fossil energy cap with trading is nearly as cost effective as a national $\mathrm{CO}_{2}$ emissions trading system that penalizes energy use based on carbon content. As a fossil energy cap builds on existing institutions in China, it offers a viable intermediate step toward a full-fledged $\mathrm{CO}_{2}$ emissions trading system.
\end{abstract}

Keywords: Climate policy, Energy cap, China, Computable general equilibrium modeling JEL: Q48, H23, C68, Q43, Q54

*Joint Program of the Science and Policy of Global Change, Massachusetts Institute of Technology, Cambridge, U.S. Email: zhangda@mit.edu.

Energy Economics 


\section{Introduction}

Policymakers in China are considering absolute limits on the use of coal and other fossil fuels to address climate change, environmental pollution, and energy security. ${ }^{1}$ For example, as part of the country's Twelfth Five-Year Plan (2011-2015), policymakers introduced a cap on coal use of 3.9 billion tons in 2015, a modest increase over the 3.6 billion tons used in 2011 (Kraemer, 2012; National Development and Reform Commission of China, 2012). ${ }^{2}$ As part of national efforts to improve air quality, policymakers announced a national cap that would limit energy consumption to 4.0 billion tons of coal equivalent by 2015 (People's Daily Online, 2013) and coal to 65\% of total primary energy use by 2017 (Xinhua Press, 2013). Regional coal caps have also been proposed in several key regions, also mainly to control air pollution (Ministry of Environmental Protection, China, 2012). Though not a binding target during the 12th Five-Year Plan, the central government has agreed to set a cap for total energy use (State Council, 2011). This intention is restated in the recently announced Party Central Committees "Guidelines for Formulating the 13th Five-Year Plan" at the Fifth Plenary Session of the 18th Central Committee of the Communist Party (Xinhua Press, 2015). This document states that "the binding targets should be strengthened, and the dual control of quantity and intensity of energy, water and land for construction should be implemented". Many provinces in China have also implemented the energy cap as a target for energy saving. For example, Jiangsu Province initiated the energy saving trading to facilitate the target achievement (Jiagsu Provincial Government, 2015). As a cap on coal or fossil energy use ${ }^{3}$ would affect the economics of energy production and use across the country, an understanding of national and regional outcomes under alternative cap designs is essential to inform sound policy decisions.

Despite the fact that there is intense discussion about introducing energy caps in China, there exists - to the best of our knowledge-no economic analysis on this class of energy policy instruments. ${ }^{4}$ This paper aims to fill this gap by investigating the cost-effectiveness and distributional impacts of alternative cap designs using a numerical general equilibrium model of the Chinese economy. Based on the most recent provincial input-output (IO) tables for all 30 provinces and China's national input-output table (National Statistics Bureau, 2011), our quantitative, empirical framework resolves all Chinese provinces and features a multi-sectoral production structure including intermediate production, specific detail on the energy sector both in terms of primary energy carriers and energy-intensive industries, and sector and fuel-specific carbon inputs.

\footnotetext{
${ }^{1}$ Often simply referred to as an energy cap, in this paper we consider a cap that excludes very low or zero carbon energy sources, such as nuclear and renewable energy. The cap would limit either coal or total fossil energy use, which in China is reported in metric tons of coal equivalent Xinhua Press (2011).

${ }^{2}$ The Twelfth Five-Year Plan's Coal Industry Development Plan assigns a production capacity target of 4.1 billion tons and a coal consumption target of 3.9 billion tons in 2015 .

${ }^{3}$ With a special interest to discuss the role of energy cap in emissions reduction, as energy and climate policies are both made by National Development and Reform Commission (NDRC) and easier to be coordinated, we are motivated to study coal or fossil energy use cap, not the cap for overall energy use.

${ }^{4}$ The idea of an energy cap has not been discussed outside of China. One possible explanation for this is that an energy cap essentially amounts to a rationing on energy consumption, something which may be only feasible in an environment with strong government regulation.
} 
A cap on coal or fossil fuels could be configured in one of several ways. It could limit coal only or all fossil energy sources. A cap could achieve a reduction in final energy demand by targeting coal only or all fossil fuels. Coal use may be an easier target for historical reasonsthere is a tradition in China of setting goals for coal capacity and total consumption during China's regular Five-Year Plan policymaking cycle. Tightening this existing mechanism may be easier than creating a new cap on all fossil fuels. Advocates of a coal cap argue that in addition to climate change, emissions from coal cause localized damage to human health and the environment, and so targeted control is appropriate. However, expanding a cap to target all fossil fuels-natural gas, oil, and coal-offers greater flexibility in terms of how $\mathrm{CO}_{2}$ emissions reductions are taken. Reducing a fixed level of final energy demand using a fossil energy cap will therefore be equally or less costly than a cap on coal only.

For a given set of fuels, a cap can also be designed in different ways. A cap could be designed to allow provinces or industries to trade energy allowances. Trading would allow entities with high abatement costs to purchase energy credits from entities that face lower costs instead of undertaking reductions themselves. The energy saving trading market is emphasized in the Twelfth Five-Year Plan for energy saving and emissions reduction (State Council, 2011). A pilot system has recently been implemented in Jiangsu, and could be expanded to other provinces (Jiagsu Provincial Government, 2015). A second issue regards whether in each province the cap should constrain energy use at the point of extraction (upstream energy use) or instead at the point where energy is used in the production of intermediate and final goods (downstream energy use). The latter includes energy use associated with production of intermediates, which may be imported.

Understanding the impacts of a cap in a sub-national framework is important because China's energy and economic system is characterized by significant heterogeneity-coal production is concentrated in the north and west regions, while demand for electricity and energy for industrial processes is highest along the more prosperous eastern seaboard. The availability of low carbon substitutes for fossil energy such as hydropower and wind also varies by region. The country's central and western provinces, in contrast to the east, are less developed. While the central and especially western provinces are major suppliers of energy, internally they use less total energy and exhibit higher energy intensity, in part due to reliance on less efficient production technology and in part due to the structure of their economies (Liu et al., 2012). Policymakers broadly agree that climate policy should not exaggerate these regional disparities, and if possible should accelerate development and technological upgrading in lagging regions.

Most of the discussion around limiting energy use in China has focused on coal (Point Carbon, 2012). Coal supplied around 70\% of China's primary energy demand in 2011 (National Statistics Bureau, 2012). Coal also has the highest carbon content of all fossil fuels and causes local pollution associated with adverse effects on human health and economic productivity (Matus et al., 2012). The notion of a coal cap in China is not new - in fact, coal consumption targets have been set in China's Five-Year Plans for decades. In several of China's recent Five-Year Plans, coal consumption targets have consistently been exceeded but the targets remain important as a planning tool (Zhang et al., 2012). Coal consumption targets announced for 2015 (and the share target announced for 2017) are likely to be implemented through targets that are set at the provincial, sector, and firm levels, a common top-down approach used to implement national energy and environmental policies in China. Several provinces and municipalities have already announced a cap 
on coal for the Twelfth Five-Year Plan (21st Century Business Herald, 2011; Xinhua Press, 2011; People's Daily Online, 2012).

In addition to selecting an appropriate target fuel or fuels, policymakers must also decide whether to allow energy allowance trading across provinces and whether to impose energy targets upstream or downstream (Reuters, 2012). In these decisions, policymakers face tradeoffs between cost-effective design and ease of implementation. For instance, achieving a national target by setting fixed reduction targets for every province overlooks the fact that some provinces may offer significant low-cost opportunities to reduce coal or fossil energy use, while marginal reductions in other provinces are much more costly. An allowance trading system would help to facilitate reductions at least cost nationwide. As of yet, no energy allowance trading mechanism has been discussed in relation to a coal or fossil energy cap. Another policy design question is whether the cap should restrict energy use upstream or downstream-all existing energy cap proposals to date target energy use upstream, although a downstream target would increase coverage (Bushnell, $2011)^{5}$. Including all fossil energy sources, allowing trading under a national cap, and targeting energy downstream would be expected to lower the overall cost of reductions by increasing coverage and thus abatement flexibility. However, implementing a cap with these features would require the development of monitoring and reporting capacity at the company and government levels, as well as the construction of exchanges for trading permits, therefore the direct administrative cost could be much higher. Scaling these systems at the national level could prove difficult to implement on a short time frame or lack the support necessary to be implemented effectively.

Our analysis contributes an assessment of energy cap designs to a rapidly growing literature on the design of energy and climate policy in China. Methodologies used to evaluate policies vary widely, from system dynamics modeling (Cong \& Wei, 2010) to distance functions and data envelopment analysis (Wei et al., 2012; Choi et al., 2012; Wei et al., 2013; Wang et al., 2013; Zhou et al., 2013) to CGE modeling (Zhang, 1998; He et al., 2010; Dai et al., 2011; Tang \& Wu, 2013; Zhang et al., 2013) to qualitative studies (Zhao \& Ortolano, 2010; Zhang et al., 2011). Many studies have used observations of regional energy intensities and abatement costs to inform the design of environmental policy in China (Zhou et al., 2011; Wei et al., 2012). Other scholarship has focused on how differences in abatement potential and costs across provinces can be used to inform reduction target assignment. While previous literature has focused on the assignment of energy or carbon intensity targets, this paper investigates a different instrument-an energy cap-and compares the efficiency and distributional impacts of different cap designs using a new regional energy-economic model of China.

The remainder of this paper is organized as follows. Section 2 provides a first descriptive analysis of energy intensity and use in China's regional energy and economic system. Section 3 describes the numerical general equilibrium model used for assessing the efficiency and distributional impacts of alternative energy cap designs as well as the scenario design used for this study. Section 4 presents the results. Section 5 concludes with a summary of results and provides a discussion of implications for energy and climate policy in China.

\footnotetext{
${ }^{5}$ China is a net importer of secondary energy. We admit that the case may be different for a region which exports large amount of intermediate energy goods. We appreciate an anonymous referee to point this out.
} 


\section{Energy intensity and embodied energy use at the provincial level}

To develop intuition for the policy analysis that follows, we first characterize China's energy system at the provincial level. We develop a global energy-economic data set that includes a consistent representation of energy markets in physical units as well as detailed accounts of regional production and bilateral trade for the year 2007. We construct data for China based on the latest available provincial input-output (IO) tables for all 30 provinces $^{6}$ and China's national inputoutput table (National Statistics Bureau, 2011). The IO tables for each province differentiate 42 sectors, and include data on existing tax rates in the Chinese economy. The global data is based on the GTAP data base (GTAP, 2012), version 8, which identifies 129 countries and regions and 57 commodities, providing consistent global accounts of production, consumption and bilateral trade as well as consistent accounts of physical energy flows, energy prices and emissions. Both underlying data sets contain observations for 2007, which facilitates integration, and each represents the latest release available. Energy use and emissions data is taken from GTAP (GTAP, 2012) and the 2007 China Energy Statistical Yearbook (National Statistics Bureau, 2008).

Compared to 42 sectors in China's provincial input-output tables, there are only 26 sectors represented in the energy balance tables. We aggregate the input-output tables to match the sectoral classification used in the energy balance tables, as shown in Table A1. The China Energy Statistical Yearbook provides detailed energy use data for each secondary industry at the national level. Provincial energy balance tables aggregate these flows at the level of 24 secondary industry sectors. We use these two sources to estimate secondary industry energy use at the provincial level. Using standard conversion factors for China (National Statistics Bureau, 2008), we aggregate the energy data to six energy product types (coal, refined oil and coal products, crude oil, natural gas, fuel gas, and electricity and heat) to be consistent with product types reported in the provincial input-output tables, as shown in Table A2. The crude oil and gas sector in IO tables is disaggregated into two sectors - Crude oil (CRU) and Natural gas (GAS) by calculating energy quantity shares from the energy balance tables.

We develop an integrated table of energy and economic flows using a least-squares optimization routine described in Zhang et al. (2013). We find substantial discrepancies between the provincial- and national-level economic accounts, consistent with the findings by Guan et al. (2012). Our estimation routine fixes the aggregate of provincial-level accounts using national totals, as national accounting methods are more standardized than provincial accounting methods. Provincial data are then used to describe the shares of economic activity in each province. To integrate physical energy flows from official statistics within the regional SAM accounts, we replace energy quantities by the value of energy flows, which are calculated as the product of physical flows and energy price data supplied by the Energy Research Institute of the National Development and Reform Commission (NDRC).

Following the methodology in Böhringer et al. (2011), we calculate embodied energy use for each primary energy type, including indirect energy use associated with non-energy inputs in addition to direct energy use. For this calculation we define the following multi-region IO model (MRIO). Let produced goods, requiring fossil fuel inputs indexed by $f$, be indexed by $i$,

\footnotetext{
${ }^{6}$ Tibet is not included due to lack of data and its small economic size.
} 


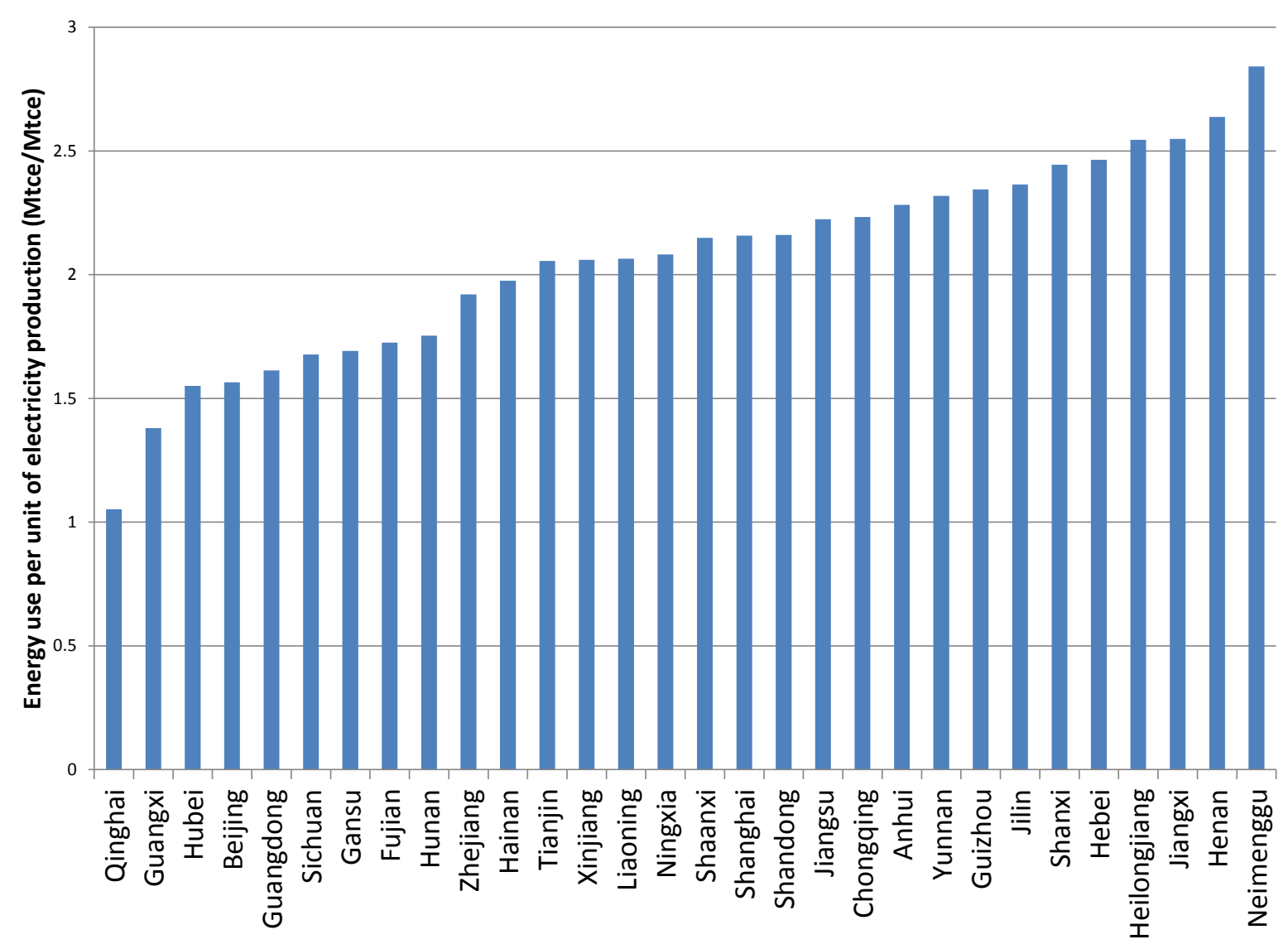

Figure 1: Fossil energy use per unit of electricity and heat sector output, by province (mtce/mtce).

and $E_{f, g, r}^{y}$ denote embodied energy $f$ for the joint set of activities - produced goods, final demand, investment, and government demand denoted by $g$ in province $r . E_{i, r}^{m}$ describes embodied energy of imported commodities defined as a weighted average of imported varieties across trade partners. In our integrated economy-energy data set, the following accounting identity holds:

$$
\bar{a}_{g, r}=\sum_{i} \bar{b}_{i, g, r}+\sum_{i} \bar{c}_{i, g, r}+\bar{d}_{g, r}
$$

where $\bar{a}, \bar{b}$, and $\bar{c}$ denote the values of output, domestic intermediate inputs, and imported intermediate inputs, respectively. $\bar{d}$ is the sum of factor and tax payments with which no energy use is associated. The multi-regional IO model relates the $E$ variables to equation (1). Embodied energy use in output is thus given by:

$$
E_{f, g, r}^{y} \bar{a}_{g, r}=\operatorname{Direct}_{\text {Energy }} \operatorname{s,g,r}+\sum_{i} \underbrace{E_{f, i, r}^{y} \bar{b}_{i, g, r}+\sum_{i} E_{f, i, r}^{m} \bar{c}_{i, g, r}}_{\text {Indirect Energy }} .
$$

Equation (2) can be represented as a square system of equations which we solve recursively using a diagonalization algorithm (Böhringer et al., 2011). 


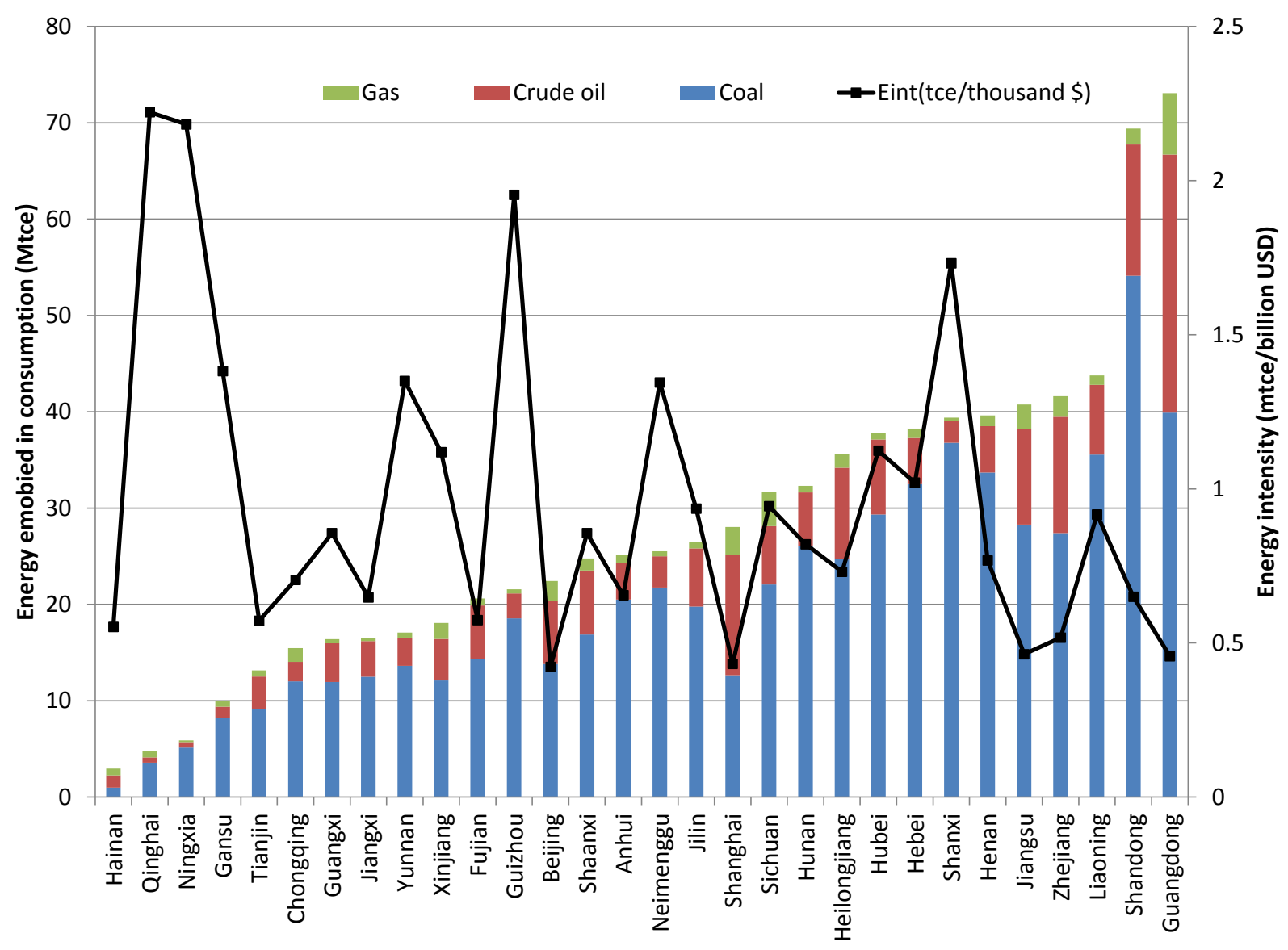

Figure 2: Total household embodied final energy use, by fuel type and energy intensity, by province.

Previous studies have analyzed the heterogeneity in patterns of energy use and $\mathrm{CO}_{2}$ emissions across China's provinces (Wang, 2011; Guo et al., 2012; Liu et al., 2012). Differences in $\mathrm{CO}_{2}$ intensity across provinces have been related to economic structure and the relative efficiency of production technology (Liu et al., 2012), although a broad range of factors are important. This section investigates the heterogeneity of China's regional energy system by considering two relevant metrics, specifically the fossil fuel intensity of electricity production, and the energy intensity of final demand. This analysis provides a foundation for interpreting model results described later in the analysis based on the numerical general equilibrium model.

Figure 1 shows the intensity of fossil energy use per unit of electricity and heat sector output. Qinghai, Guangxi and Hubei have large shares of hydroelectric generation that lead to a lower fossil fuel intensity of electricity generation. Provinces differ greatly in terms of both the composition and the efficiency of electric power generation. Some provinces have significant room to improve the fossil fuel efficiency of generation through fuel switching, investment in efficiency upgrades, or new construction of low carbon renewable or nuclear generation. The availability and relative cost of these opportunities will determine to a large extent the cost of abatement in the electricity sector of each province.

Figure 2 shows that provinces also differ in terms of the total energy associated with final 
Table 1: Regional aggregation in the model.

\begin{tabular}{lll}
\hline \hline China's provinces & Other regions & \\
\hline $\begin{array}{l}\text { 30 provinces (including 4 municipal } \\
\text { cities and 5 autonomous regions) }\end{array}$ & EUR & Europe (EU 27 + EFTA) \\
$\begin{array}{l}\text { in total, and Tibet is not included } \\
\text { due to lack of available data. }\end{array}$ & & $\begin{array}{c}\text { Asian and Pacific developed countries or } \\
\text { regions (Japan, Korea, Singapore, Taiwan, }\end{array}$ \\
& ASI & Australia and New Zealand) \\
& NAM & Other Asian countries \\
& CAA & Corth America (U.S. and Canada) \\
& ROW & Latin America and rest of the world \\
\hline
\end{tabular}

household demand calculated by the MRIO approach. Provinces that consume large amounts of energy are among the least energy intensive. For example, Guangdong has the highest total household energy use but the lowest energy intensity. Shandong, Zhejiang, and Jiangsu exhibit similar patterns. By contrast, Ningxia and Qinghai rank among the highest in terms of energy intensity of household consumption but lowest in terms of total energy use by households.

Given the large heterogeneity in energy intensity and use across Chinese provinces, it is obvious that the cost-efficiency and distributive impacts hinge on the specific design of alternative energy caps. In particular, the efficiency of energy cap instruments will depend on their potential to enable reductions in energy consumption in provinces with low costs to save energy. For example, a policy that disproportionately targets populous provinces with a high level of energy use may miss significant (and likely cost-effective) energy saving opportunities in the center and western parts of the country.

\section{The model and scenario design}

\subsection{Model}

We investigate the effects of alternative energy cap designs using a general equilibrium model built on the data set described in the previous section. We employ the China Regional Energy Model (C-REM), a multi-commodity, multi-regional static numerical general equilibrium model of the global economy with provincial detail in China (see Zhang et al. (2013) for model details, including production and household consumption structure, supplies of final goods and treatment of domestic and international trade, elasticities of substitution in production and consumption functions, and equilibrium conditions and model solution). For this study, we aggregate the global data set to 30 provinces in China and six world regions (see Table 1), and into 16 commodity groups produced by the sectors defined above. We distinguish six energy goods (coal, natural gas, fuel gas, crude oil, refined oil and electricity) and 10 non-energy commodities (see Table 2). The key features of the model are outlined below.

We acknowledge that the static model applied in this study does not include the adoption of advanced technology nor does it capture the differential growth rates across provinces expected in 
Table 2: Sectoral aggregation in the model.

\begin{tabular}{lll}
\hline \hline Sector & Abbreviation & Sectors aggregated from GTAP 8 data set \\
\hline Agriculture & AGR & PDR, WHT, GRO, V_F, OSD, C_B, PFB \\
& & OCR, CTL, OAP, RMK, WOL, FRS, FSH \\
& & CMT, OMT, VOL, MIL, PCR, SGR \\
Coal & COL & COL \\
Crude oil & CRU & CRU \\
Natural gas & GAS & GAS \\
Minerals mining & OMN & OMN \\
Light industries & LID & FBT, TEX, WAP, LEA, LUM, PPP \\
Petroleum, coal products & OIL & OIL \\
Energy intensive industries & EID & CRP, NMM, I_S, NFM \\
Transport equipment & TME & MVH, OTN \\
Other manufacturing industries & OID & FMP, OME, ELE, OMF, CNS \\
Electricity & ELE & ELY \\
Gas manufacture and distribution & GDT & GDT \\
Water & WTR & WTR \\
Trade & TRD & TRD \\
Transport & TRP & OTP, WTP, ATP \\
Other service industry & OTH & CMN, OFI, ISR, OBS, ROS, OSG, DWE \\
\hline
\end{tabular}

the years ahead. Thus our projection represents a short-run projection of the coal cap's impact.

\subsection{Scenario design}

To compare energy cap designs on a consistent basis, all designs modeled achieve a $20 \%$ reduction in fossil energy use associated with final demand across all sectors, households, government and investment activities. ${ }^{7}$ Our modeling approach is intended to simulate the impact of reducing energy use by $20 \%$ relative to a business-as-usual trajectory. ${ }^{8}$ We believe this assumption is plausible given that we focus on policies acting over a relatively short time frame (the Twelfth Five-Year Plan, 2011-2015). We simulate an energy cap in the C-REM model as an endogenous tax on either coal or fossil energy use. The level of the tax is determined by the marginal cost of energy reduction required to meet the national constraint on final energy demand. In scenarios with energy allowance trading, provinces facing a high cost of energy reductions purchase allowances from provinces where marginal costs are lower via a national allowance market. The initial allocation of allowances under the trading system is based on the total final energy consumption in each province.

\footnotetext{
${ }^{7}$ Intermediate energy demand (e.g. demand associated with electricity generation and coke production) is not directly constrained. The term "downstream" is often used to refer to this convention for assigning policy, which targets energy use associated with final demand (Jotzo, 2013).

${ }^{8}$ As we perform the simulation in a static framework, we assume that the underlying structure of the economy changes only in response to changes in relative prices.
} 
The objective of the first set of scenarios is to compare a coal cap and a fossil energy cap in terms of the national and regional changes in the energy mix as well as the associated welfare impacts that result under each policy. These scenarios are defined as follows:

- COAL_CAP: Achieves a 20\% reduction in final fossil energy use at the national level by capping coal upstream and implementing the cap through provincial targets (with no coal allowance trading market).

- FOSSIL_CAP: Achieves a 20\% reduction in final fossil energy use at the national level by capping all downstream energy use and allowing energy allowance trading across provinces.

- CO2_CAP: Achieves the same national reduction in $\mathrm{CO}_{2}$ emissions as FOSSIL_CAP by capping downstream $\mathrm{CO}_{2}$ emissions and allowing trading of emissions permits across provinces.

We first model a coal cap based on the current design under discussion. Specifically, the cap targets reductions in provincial coal use upstream (with no allowance trading across provinces). We compare the coal-only cap to a cap on downstream fossil energy use (coal, natural gas, and oil) with an energy allowance trading market. Finally, given that the objective of the energy cap is in part to address $\mathrm{CO}_{2}$ emissions, we then compare the fossil energy cap to a cap on $\mathrm{CO}_{2}$ emissions. This cap reduces $\mathrm{CO}_{2}$ emissions by a level identical to the fossil energy cap. By targeting $\mathrm{CO}_{2}$ emissions directly, the cap would be expected to lower the cost of reductions, relative to an energy cap policy that does not differentiate energy sources based on $\mathrm{CO}_{2}$ emissions intensity.

We then compare alternative fossil energy cap designs. Specifically, we consider additional variants of a fossil energy cap-either by requiring reductions at the provincial level, targeting reductions upstream, or both. We therefore consider an additional set of scenarios:

- NCAP_DOWN: Same as FOSSIL_CAP above, achieves a 20\% reduction nationwide by capping fossil energy use downstream and allowing energy allowance trading across provinces.

- NCAP_UP: Achieves a 20\% reduction nationwide by capping fossil energy use upstream and allowing energy allowance trading across provinces.

- RCAP_DOWN: Achieves a 20\% reduction in each province by capping fossil energy use downstream with no trading across provinces.

- RCAP_UP: Achieves a 20\% reduction in each province by capping fossil energy use upstream with no trading across provinces.

\section{Results}

We first compare coal and fossil energy caps in terms of their national and regional impacts on the energy mix, downstream fossil energy use, and the incidence of economic costs. We then compare the fossil energy cap to a national cap on $\mathrm{CO}_{2}$ emissions. Another set of scenarios considers alternative designs for the fossil energy cap, to evaluate the impact of allowance trading and upstream versus downstream implementation. 


\subsection{National impacts}

We begin by comparing a coal cap to a fossil energy cap. Both policies achieve an identical reduction in final fossil energy use but under each policy the source of reductions is different. We find that if a national reduction in fossil energy of $20 \%$ were achieved entirely by reducing coal, coal use would fall by $30 \%$. A coal cap also indirectly causes a reduction of other fossil energy types because higher coal prices increase the cost of final goods, reducing overall demand. Under a coal cap, demand for refined oil and coke products and natural gas falls by about $7 \%$ and $2 \%$ respectively. By comparison, a fossil energy cap also reduces coal use, but only by $27 \%$, while natural gas demand falls by $17 \%$ and demand for refined oil and coke products falls by around $7 \%$. The modest reduction in oil use reflects its high marginal cost of abatement, given that there are few substitutes for oil in the parts of the economy where it is primarily used, such as the transportation sector.

We then compare the results of the fossil energy cap policy to a constraint on $\mathrm{CO}_{2}$ emissions that achieves an identical emissions reduction, and find that patterns of energy use reduction differ only slightly: under an equivalent $\mathrm{CO}_{2}$ emissions constraint, coal is reduced by $28 \%$, while natural gas falls by $11 \%$ and refined oil and coke products by $6 \%$. The slightly larger contribution from coal reflects the fact that coal has a higher carbon content than oil or natural gas, and thus under a policy that targets carbon rather than energy, it is cost effective to pursue larger reductions from coal. However, it is interesting that the fossil energy cap-a more blunt instrument-produces an outcome that comes fairly close to that of a national $\mathrm{CO}_{2}$ emissions constraint. Our model results suggest that in China coal can be reduced cost effectively compared to other energy types, whether it be on a carbon or an energy basis.

Turning to the welfare impacts, we find that at the national level, the coal cap causes the largest loss in welfare, measured as equivalent variation $(\mathrm{EV})$ relative to reference, at $-3.0 \%$, while both the downstream fossil energy/emissions cap with trading results in a loss in EV of only $-1.6 \%$. The magnitude of this advantage depends on the design of the coal and fossil energy cap. We also test a national cap on coal and find that it results in a lower welfare loss of $-2.7 \%$. This loss is still greater than the loss expected under the least cost effective of the fossil energy cap designs modeled, a provincial cap that acts by constraining fossil energy use upstream, which has a welfare loss of $-2.6 \%$. The higher welfare loss under the coal cap can be mainly attributed to the limited strategies available for abating other fossil energy use. The fact that reductions are regionally determined and limited to upstream sources further contributes to the high cost of the coal cap.

\subsection{Regional impacts}

We now turn to the provincial distribution of policy impacts. We retain provincial detail in presenting the results, given that we find impacts differ significantly (in magnitude as well as sign) in neighboring provinces. These differences would be obscured in a higher level of aggregation. Policy impacts can be explained in terms of differences across provinces in the fossil energy intensity of production (see Section 2), energy mix composition, and the associated marginal costs of abatement. Figure 3 shows final fossil energy use under each of the policy scenarios compared to a No Policy reference case. We find that the coal cap results in much more significant reductions in coal use in relatively affluent provinces (Beijing, Tianjin, and Shanghai) relative to either a fossil 


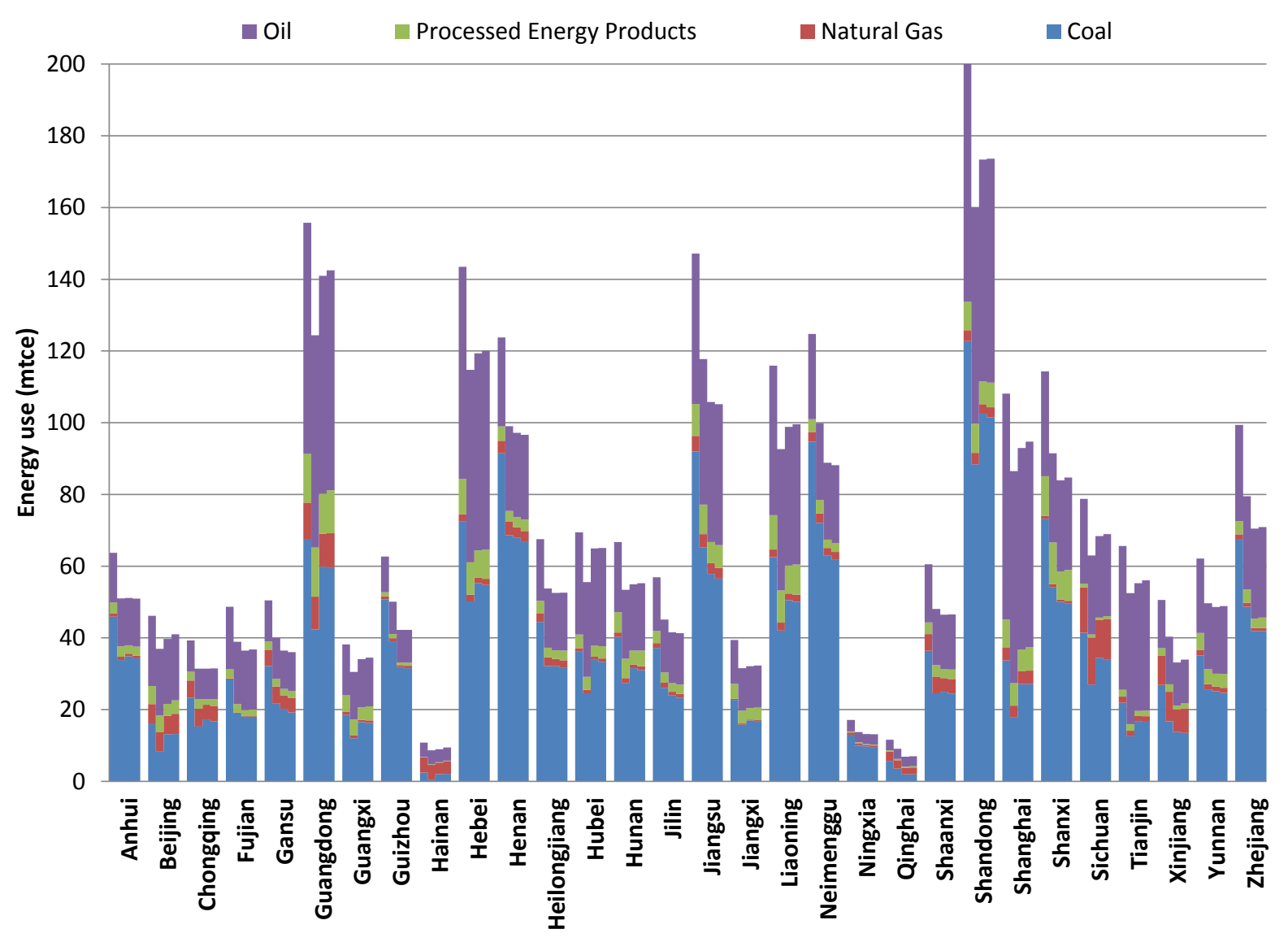

Figure 3: Final fossil energy use under each of the policy scenarios compared to a No Policy reference case (from left to right for each province: No Policy, COAL_CAP, FOSSIL_CAP and CO2_CAP).

energy cap or carbon policy. By contrast, Shanxi, Inner Mongolia, Guizhou, and Xinjiang—all resource rich, less developed provinces-would reduce coal more under a national fossil energy or carbon target, reflecting an abundance of low cost opportunities in these provinces.

Provincial welfare changes also vary widely across provinces, showing different patterns under alternative policies. Figure 4 shows the consumption loss under the coal cap, fossil energy cap, and carbon cap policies by province. It is perhaps unsurprising that under the coal cap we find large concentrated welfare costs in provinces that have small shares of coal in final fossil energy consumption (see Figure 5). Achieving the same relative reduction of coal in these provinces costs more because in many cases relatively inexpensive substitution opportunities have been exhausted and there are few (or relatively costly) substitutes for residual coal uses. It is also worth noting that a higher share of coal conversion (coal that is converted to coking products and fuel gas) is correlated with reduced provicial welfare loss (see Figure 6). Under a coal cap, the prices of conversion products also rise, and thus provinces that are competitive exporters of these products will benefit from increased revenues. This may largely explain why Shanxi, the largest coal producer, bears a lower welfare loss than Ningxia, another major coal producing province.

Both the fossil energy cap and the carbon cap result in similar patterns of welfare loss across provinces. This result is not surprising given that the only difference between the two policies is 


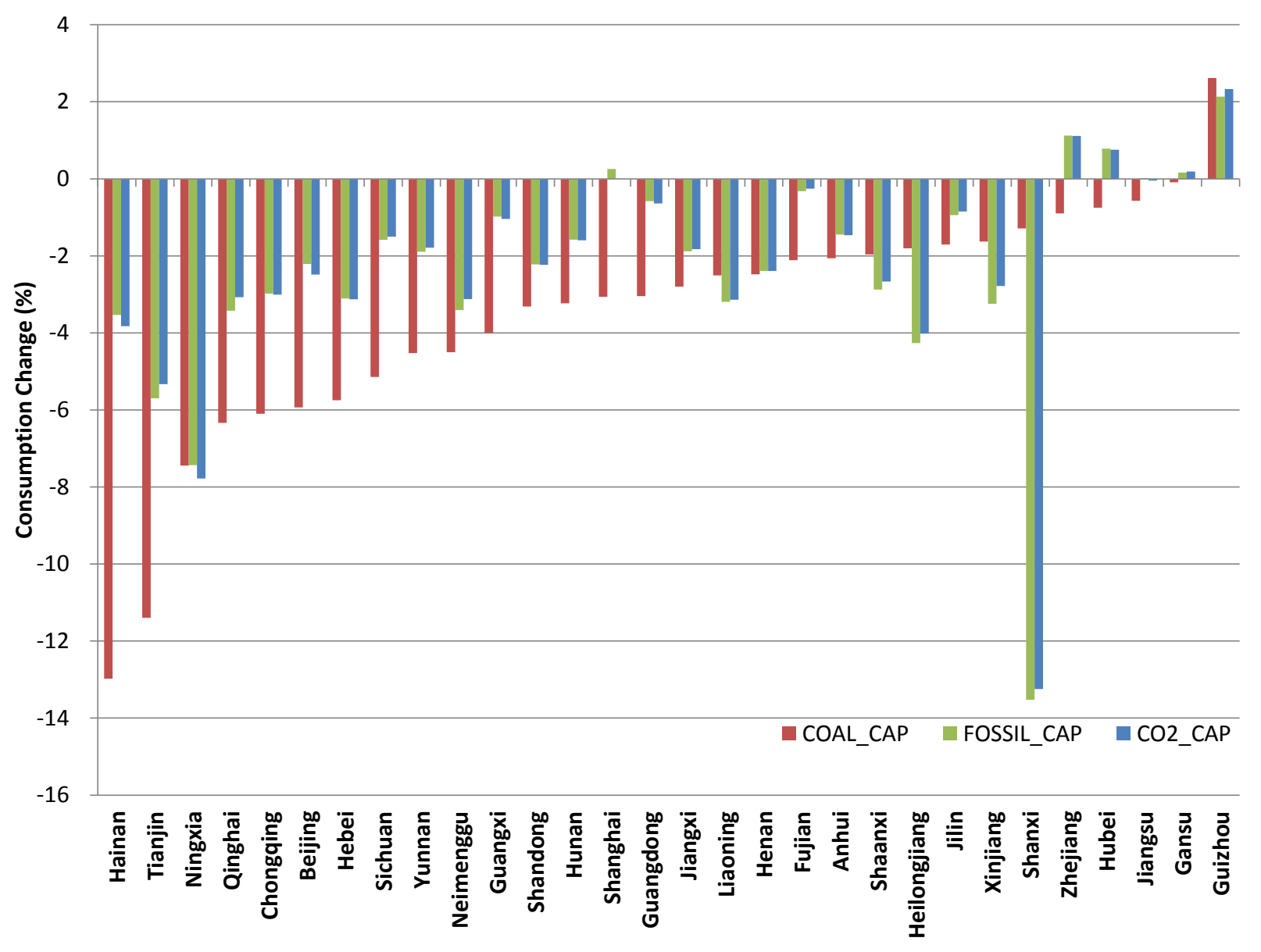

Figure 4: Consumption change in percent under the COAL_CAP, FOSSIL_CAP and CO2_CAP scenarios.

that the carbon cap penalizes carbon content rather than energy use, and coal provides the dominant cost-effective source of abatement under both policies. Both the fossil energy cap and the carbon cap allow inter-provincial trading that takes advantages of the large, concentrated availability of abatement opportunities in some provinces. Therefore, for many provinces, losses under a fossil energy or carbon cap are less pronounced relative to the losses under the coal cap. However, consumption losses in the coal-rich provinces Shanxi, Ningxia, Heilongjiang, Xinjiang and Shaanxi are larger under the fossil energy cap and carbon cap scenarios because these provinces offer an important source of low-cost abatement nationwide. A coal cap implemented on a provincial basis spares these provinces massive adjustments in their coal industries by placing an upper limit on the share of abatement they shoulder. This is an example of the tradeoff between national and provincial targets, as the lower cost abatement opportunities that national policies exploit tend to be concentrated in just a few provinces.

\subsection{Comparing energy cap policy designs}

We now consider alternative designs for a fossil energy cap. The energy cap design considered above targeted least-cost reductions in downstream energy use nationwide. However, an upstream cap that targets reductions at the provincial level may be more compatible with China's existing 


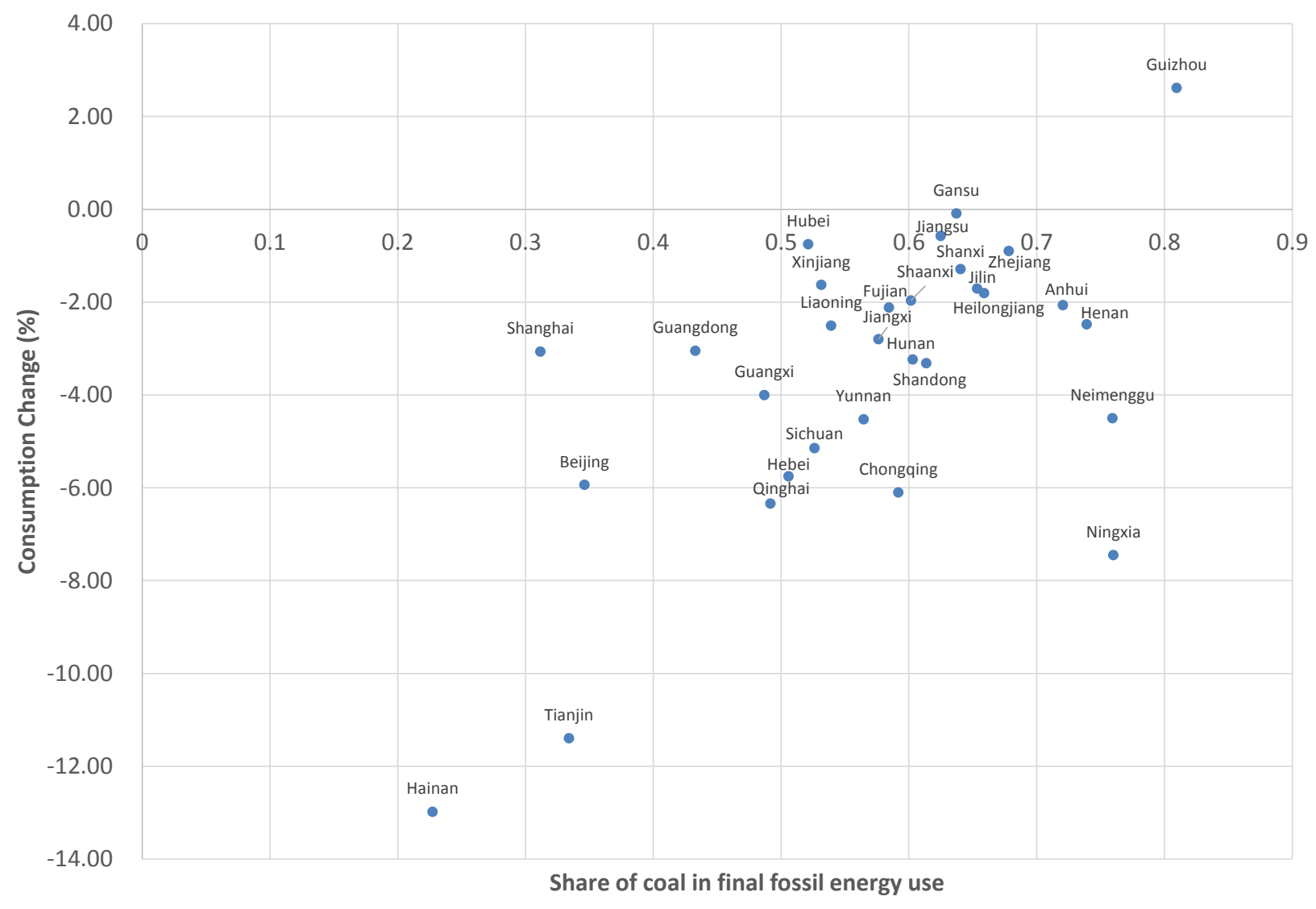

Figure 5: Share of coal in final fossil energy use and consumption change in percent under the COAL_CAP scenario.

policy institutions and implementation channels. Moreover, national allowance trading would require new institutions to facilitate and oversee permit exchange. It may also prove more feasible to cap energy consumption upstream instead of downstream, given that upstream energy use is easier to track (Jotzo, 2013). Therefore, it is important to consider these alternative-potentially more feasible - cap designs, and how they would affect welfare outcomes. We study the cost associated with each of these alternative designs. We further test the sensitivity of the results to the stringency of the cap (see Table 3).

Provincial targets spread the burden for reducing fossil energy use equally across provinces but with the result that abatement is undertaken at different marginal costs, raising the overall cost of the policy. At the national level, the welfare penalty for moving from a national to a provincial fossil energy cap is a $31 \%$ increase in the welfare loss to $-2.1 \%$. Capping energy use upstream instead of downstream also negatively affects welfare. Moving to upstream targets increases the welfare loss by $13 \%$. This effect is exaggerated in a provincial targets setting. If trading across regions is not permitted, the change in welfare loss increases to $63 \%$.

The sensitivity analysis tests the impact of changing target stringency on the relative costeffectiveness of the policy designs considered. Compared to a base case reduction of $20 \%$, increasing the target stringency to $30 \%$ or reducing it to $10 \%$ did not affect the cost-effectiveness 


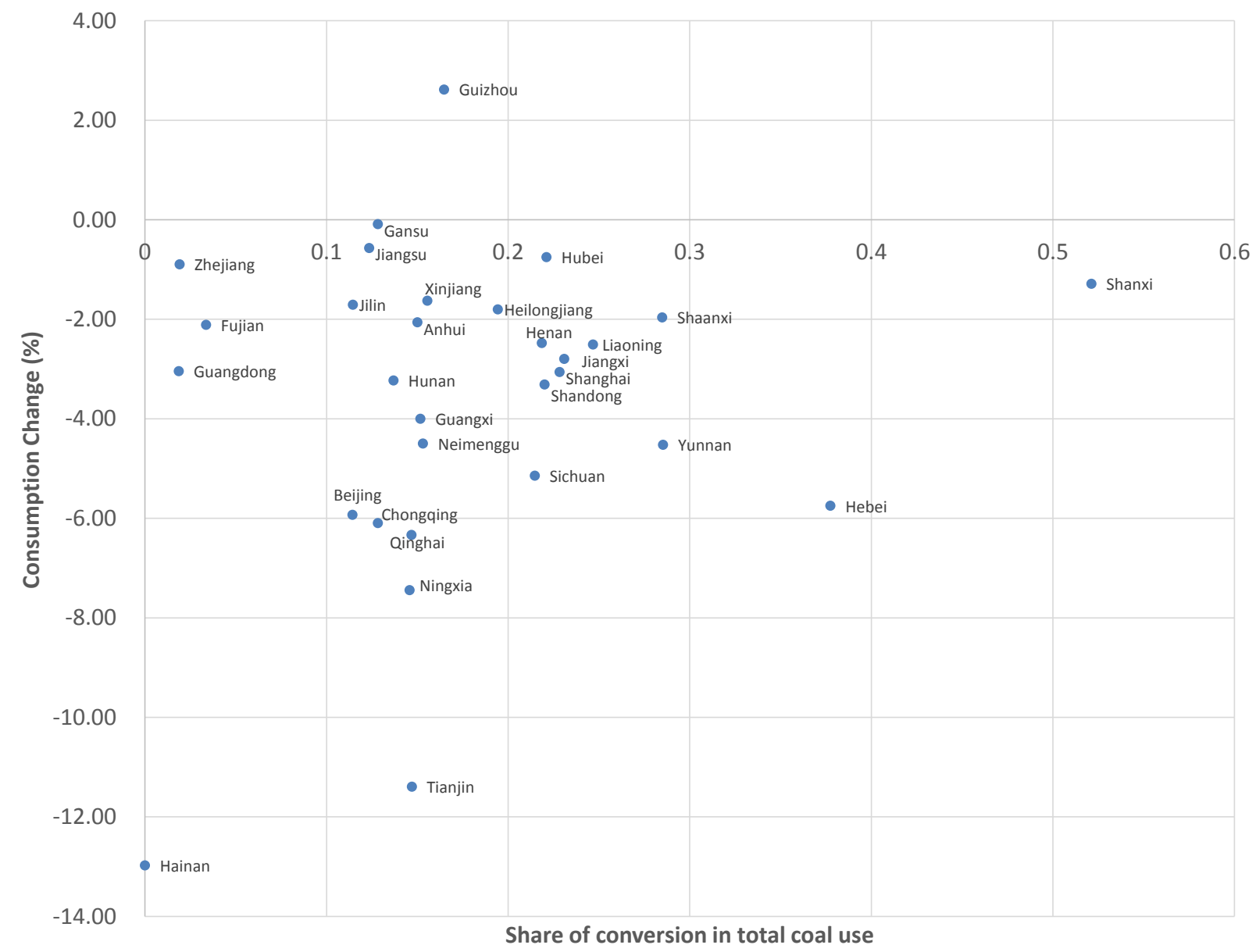

Figure 6: Share of coal conversion in total coal use under the COAL_CAP scenario.

ranking of policy designs. However, we note that as target stringency increases, targeting upstream rather than downstream energy leads to a larger incremental welfare decrease, especially in the provincial policy scenarios.

\subsection{Impact on non-fossil energy}

As excluding nuclear, hydro, wind, and other non-fossil resources from the cap is tantamout to reducing their costs relative to fossil energy sources, we expect an increase in non-fossil sources under the cap. Indeed, we found in an increase in non-fossil energy use in every province under all energy cap scenarios. Since non-fossil energy use is calibrated to its base-year levels, the increase in non-fossil energy under policy, which in our model includes nuclear, hydro, and wind electricity, is essential proportional to this initial level ${ }^{9}$.

\footnotetext{
${ }^{9}$ In our static model, our representation of non-fossil energy is deliberately simple. A dynamic, especially a longterm projection of energy or coal cap impacts would benefit from a detailed representation of advanced technology options. Our results here are intended to capture a short-run effect of each policy and would therefore be expected to be robust to our simplifying assumptions.
} 
Table 3: Welfare change at the national level under different fossil energy cap designs.

\begin{tabular}{lrrrr}
\hline \hline Reduction target & NCAP_DOWN & NCAP_UP & RCAP_DOWN & RCAP_UP \\
\hline $20 \%$ & $-1.6 \%$ & $-1.8 \%$ & $-2.1 \%$ & $-2.6 \%$ \\
$10 \%$ & $-0.4 \%$ & $-0.4 \%$ & $-0.5 \%$ & $-0.6 \%$ \\
$30 \%$ & $-3.9 \%$ & $-4.4 \%$ & $-4.9 \%$ & $-6.8 \%$ \\
\hline
\end{tabular}

\section{Conclusions}

Our analysis offers some robust insights for energy and climate policy design in China. First, we find that capping all fossil energy sources is always more cost effective than capping coal only. This conclusion holds regardless of the design of the fossil energy cap. ${ }^{10}$ A fossil energy cap is more cost effective than a coal cap because it allows reductions to be achieved through abatement of other fossil energy sources. The high cost of achieving reductions through a coalonly cap is magnified by its larger overall negative impact on economic activity, an indirect general equilibrium effect that we show here is important, but is typically not considered in the policy process. Excluding $\mathrm{CO}_{2}$ intensive primary fuels, such as natural gas and oil, from an energy cap indirectly subsidizes these fuels, offsetting the environmental and climate benefits of a coal cap.

Second, we find that a fossil energy cap may be a suitable near-term substitute for a $\mathrm{CO}_{2}$ emissions cap. This is because coal is a major source of low-cost reductions in both energy and emissions, and contributes significantly to reductions under both policies. An energy cap could support efforts to develop consistent energy and $\mathrm{CO}_{2}$ emissions inventories across the economy. Specifically, by strengthening national energy accounting, a fossil energy cap could lay the foundation for moving to a cap based on energy-related $\mathrm{CO}_{2}$ emissions. Given that $\mathrm{CO}_{2}$ emissions inventories at the provincial, sector, industry, and firm level are only in the early stages of development, a fossil energy cap could create the institutional framework while $\mathrm{CO}_{2}$ emissions accounts are established and standardized in parallel.

In policy discussion, it has often been pointed out that a fossil energy cap would indirectly penalize low carbon fuels, such as natural gas, due to the high cost of production. Our results emphasize that it is essential not to conflate the cost of production with marginal abatement cost, as the latter determines which reductions are most cost effective. We find that natural gas is reduced only slightly more under a fossil energy cap relative to a carbon cap, and the opposite is found for coal, which is reduced slightly less. As coal is inexpensive vis-à-vis natural gas, the shadow price established implicitly by an energy or carbon cap causes an larger increase in the relative price of coal. This policy-induced price increase is much smaller in the case of natural gas. Therefore, neither policy is likely to target reductions in natural gas at the expense of reductions in

\footnotetext{
${ }^{10}$ For all cases, we assume that the costs of compliance with policy are passed through to final users. However, China has managed electricity pricing (Lam, 2004), and so some end-use decisions would not respond to the policy, reducing overall cost effectiveness. However, we do not expect the results to change if the assumption of managed electricity pricing is imposed consistently in all scenarios considered.
} 
coal. Regardless of whether energy or $\mathrm{CO}_{2}$ is targeted, reducing coal use proves to be a dominant abatement strategy.

While cost-effective design is important to minimizing the economic impacts of policy, in practice policies that build on existing institutions and practices may stand a greater chance of implementation. A coal cap may be easier to implement because it focuses on a single commodity, and has perhaps the strongest policy precedent in China. Our analysis illustrates the costs of this approach - a similar amount of energy can be reduced through a national fossil energy cap with allowance trading at only about $55 \%$ of the cost of a coal-only cap. When it comes to cap design, we find that a national constraint on downstream energy use is the most cost effective. Assigning targets at the provincial level and/or on energy use upstream carries an incremental welfare penalty of $13 \%$ to $63 \%$, relative to a policy that constrains final energy demand at the national level. Despite these welfare penalties, alternative policy designs may prove more politically feasible. Policy targets in China have traditionally been implemented through regional channels, with enforcement delegated to provincial governments. Regional policies may also limit the direct impact on the energy system in some provinces, particularly those that are centers of coal production. We find that moving from national to provincial fossil energy targets carries a modest welfare penalty. The welfare penalty, however, is larger when moving from downstream to upstream targets, particularly if implemented at the provincial level. The welfare penalties associated with potentially more feasible alternative policy designs should be considered explicitly in policy discussions.

While a fossil energy cap may be a reasonable substitute for an explicit constraint on carbon at least for the levels of stringency we consider here, it would fail to address another major concern of China's policymakers-reliance on imported oil. Neither a fossil energy cap nor a carbon cap would lead to significant reductions in petroleum demand, given the lack of substitutes for its use in transportation and chemical production. If energy security is the desired objective, additional policies will be needed.

By comparing energy cap designs, we show that all caps are not created equal, and policy makers face trade-off when comparing the administrative cost, economic adjustment cost, and cobenefits of different policy designs. If deep reductions in coal use are desired for environmental reasons, policymakers should be aware that marginal costs may be high and negative economic impact concentrated in a few provinces. Given that coal is also tied to degraded air and water quality, local as well as aggregate costs and benefits will need to be carefully considered. Here, we compare policies based on a cost-effectiveness metric, the welfare change (measured as equivalent variation) associated with achieving a given coal cap goal. We do not quantify the benefits, direct or indirect, that result from the introduction of each policy, as this would require additional assumptions or an atmospheric chemistry and health effects modeling effort to estimate. However, we note that the change in coal use nationally under the coal cap and energy cap is actually quite similar, with a $27 \%$ reduction under the energy cap compared to a $30 \%$ reduction under the coal cap. While coal reduction is greater in a few populous regions such as Beijing, Tianjin and Guangdong under a coal cap relative to an energy cap, it is unlikely that the additional coal reduction under the coal cap reduces pollution (and avoids health costs) to the point that it would reverse the order of policy preference that our cost-focused analysis implies.

However, if the goal is slowing the growth in fossil energy demand and mitigating climate change, fossil energy or $\mathrm{CO}_{2}$ emissions are more appropriate targets. As an energy cap on final 
fossil fuel demand and on $\mathrm{CO}_{2}$ emissions are similar in terms of cost effectiveness, if both are implemented, these two instruments would be redundant. If the only goal were to reduce $\mathrm{CO}_{2}$ emissions, targeting $\mathrm{CO}_{2}$ directly would be best, but our analysis suggests that a fossil energy cap on downstream energy with trading could be an acceptable substitute. A national fossil energy cap could also constitute as possible intermediate step between today's targets on coal use and a fullfledged $\mathrm{CO}_{2}$ emissions trading system. This approach would allow for the parallel development of institutions to support $\mathrm{CO}_{2}$ emissions accounting and inter-provincial trading. Our analysis underscores the general point that a sharp policy instrument is always preferred to a blunt instrument, but that some blunt instruments are sharper than others.

\section{Acknowledgements}

We acknowledge the support of the Ministry of Science and Technology of China through the Institute for Energy, Environment, and Economy at Tsinghua University. We further thank the French Development Agency (AFD), Eni S.p.A., ICF International, and Shell International Limited, founding sponsors of the China Energy and Climate Project. We are grateful for support provided by the Social Science Key Research Program from National Social Science Foundation, China of Grant No. 09\&ZD029 and by Rio Tinto China. We would further like to thank John Reilly, Sergey Paltsev, Kyung-min Nam, Henry Chen, Paul Kishimoto as well as participants in the 31st USAEE/IAEE North American Conference in Austin for their constructive comments and insightful discussion of our paper. We also acknowledge the support of the MIT Joint Program on the Science and Policy of Global Change, and in particular the U.S. Department of Energy Integrated Assessment Grant (DE-FG02-94ER61937).

\section{References}

21st Century Business Herald (2011). Nine regions have set initial coal consumption caps.

Böhringer, C., Carbone, J. C., \& Rutherford, T. F. (2011). Embodied carbon tariffs. NBER Working Paper 17376.

Bushnell, E. T., James B.and Mansur (2011). Vertical targeting and leakage in carbon policy. The American Economic Review, 101, 263-267.

Choi, Y., Zhang, N., \& Zhou, P. (2012). Efficiency and abatement costs of energy-related $\mathrm{CO}_{2}$ emissions in China: A slacks-based efficiency measure. Applied Energy, 98, 198-208.

Cong, R.-G., \& Wei, Y.-M. (2010). Potential impact of (CET) carbon emissions trading on China's power sector: A perspective from different allowance allocation options. Energy, 35, 3921-3931.

Dai, H., Masui, T., Matsuoka, Y., \& Fujimori, S. (2011). Assessment of China's climate commitment and non-fossil energy plan towards 2020 using hybrid AIM/CGE model. Energy Policy, 39, 2875-2887.

GTAP (2012). Global Trade, Assistance, and Production: The GTAP 8 data base. Center for Global Trade Analysis, Purdue University.

Guan, D., Liu, Z., Geng, Y., Lindner, S., \& Hubacek, K. (2012). The gigatonne gap in China's carbon dioxide inventories. Nature Climate Change, 2, 672-674.

Guo, J., Zhang, Z., \& Meng, L. (2012). China's provincial $\mathrm{CO}_{2}$ emissions embodied in international and interprovincial trade. Energy Policy, 42, 486-497.

He, Y. X., Zhang, S. L., Yang, L. Y., Wang, Y. J., \& Wang, J. (2010). Economic analysis of coal price - electricity price adjustment in China based on the CGE model. Energy Policy, 38, 6629-6637.

Jiagsu Provincial Government (2015). Inform on the Management Rules for Energy Saving Trading.

Jotzo, F. (2013). Emissions trading in China: Principles, design options and lessons from international practice. CCEP Working Paper 1303 Crawford School of Public Policy, Australian National University. 
Kraemer, S. (2012). China to simply cap coal use within 3 years. Scientific American.

Lam, P.-L. (2004). Pricing of electricity in China. Energy, 29, 287-300.

Liu, Z., Geng, Y., Lindner, S., \& Guan, D. (2012). Uncovering China's greenhouse gas emission from regional and sectoral perspectives. Energy, 45, 1059-1068.

Matus, K., Na, K.-M., Selin, N. E., Lamsal, L. N., Reilly, J. M., \& Paltsev, S. (2012). Health damages from air pollution in China. Global Environmental Change, 22, 55-66.

Ministry of Environmental Protection, China (2012). Inform on issuing the plan of air pollution control in key areas during the 12th Five-Year Plan.

National Development and Reform Commission of China (2012). Twelfth Five-Year Plan Coal Industry Development Plan.

National Statistics Bureau (2008). 2007 China Energy Statistical Yearbook.

National Statistics Bureau (2011). 2007 China Regional Input-Output Tables.

National Statistics Bureau (2012). 2012 China Statistical Yearbook.

People's Daily Online (2012). Wu Yin: China's coal consumption in 2015 should be controlled within 3.9 billion ton.

People's Daily Online (2013). Energy Development 12th Five-Year Plan set energy consumption limit to 4.0 billion tons of coal equivalent.

Point Carbon (2012). China's Tianjin sets 2015 coal consumption cap.

Reuters (2012). China may miss new target to cut coal output growth.

State Council (2011). Inform on the Comprehensive Work Plan on Energy Saving and Emissions Reduction in the 12th Five-Year Plan.

Tang, W., \& Wu, L. (2013). Efficiency or Equity? Simulating the Carbon Emission Permits Trading Schemes in China Based on an Inter-Regional CGE Model. 16th Annual Conference on Global Economic Analysis.

Wang, K., Zhang, X., Wei, Y.-M., \& Yu, S. (2013). Regional allocation of $\mathrm{CO}_{2}$ emissions allowance over provinces in China by 2020. Energy Policy, 54, 214-229.

Wang, X. (2011). On China's energy intensity statistics: Toward a comprehensive and transparent indicator. Energy Policy, 39, 7284-7289.

Wei, C., Löschel, A., \& Liu, B. (2013). An empirical analysis of the $\mathrm{CO}_{2}$ shadow price in Chinese thermal power enterprises. Energy Economics, 40, 22-31.

Wei, C., Ni, J., \& Du, L. (2012). Regional allocation of carbon dioxide abatement in China. China Economic Review, $23,552-565$.

Xinhua Press (2011). Shandong Province will cap coal consumption during the Twelfth Five-Year Plan.

Xinhua Press (2013). China will limit coal to 65\% of total primary energy use by 2017.

Xinhua Press (2015). Guidelines for Formulating the 13th Five-Year Plan.

Zhang, D., Rausch, S., Karplus, V., \& Zhang, X. (2013). Quantifying regional economic impacts of $\mathrm{CO}_{2}$ intensity targets in China. Energy Economics, 40, 687-701.

Zhang, F., Guo, Y., \& Chen, X. (2011). Research on China's power sector carbon emissions trading mechanism. Energy Procedia, 12, 127-132.

Zhang, Q., He, K., \& Huo, H. (2012). Cleaning China's air. Nature, 484, 161-162.

Zhang, Z. (1998). Macroeconomic effects of $\mathrm{CO}_{2}$ emission limits: A computable general equilibrium analysis for China. Journal of Policy Modeling, 20, 213-250.

Zhao, X., \& Ortolano, L. (2010). Implementing China's national energy conservation policies at state-owned electric power generation plants. Energy Policy, 38, 6293-6306.

Zhou, J., Duan, M., \& Liu, C. (2011). Output-based allowance allocations under China's carbon intensity target. Energy Procedia, 5, 1904-1909.

Zhou, P., Zhang, L., Zhou, D., \& Xia, W. (2013). Modeling economic performance of interprovincial $\mathrm{CO}_{2}$ emission reduction quota trading in China. Applied Energy, 112, 1518-1528. 


\section{Appendix}

Table A1: Sector mapping of China's provincial input-output tables using overlapping sectors with energy balance tables

\begin{tabular}{|c|c|}
\hline Sector before aggregation & Sector abbreviation after aggregation \\
\hline Agriculture & AGR \\
\hline Coal mining and processing & $\mathrm{COL}$ \\
\hline Crude petroleum and natural gas & CRG \\
\hline Metal minerals mining & MMN \\
\hline Non-metal minerals and other mining & NMN \\
\hline Food, beverage and tobacco & FBT \\
\hline Textiles & TEX \\
\hline Wearing apparel, leather and furs & CLO \\
\hline Logging and transport of timber and furniture & LUM \\
\hline Paper, printing and other products for education and sports & PPP \\
\hline Petroleum refining, coking products and nuclear fuels & OIL \\
\hline Chemical engineering & CRP \\
\hline Non-metallic mineral products & NMM \\
\hline Metal smelting and processing & MSP \\
\hline Metal product & FMP \\
\hline General and special industrial machinery and equipment & OME \\
\hline Transport machinery and equipment & TME \\
\hline Electric machinery and equipment & EME \\
\hline $\begin{array}{l}\text { Communication, computer and } \\
\text { other electronic machinery and equipment }\end{array}$ & ELQ \\
\hline $\begin{array}{l}\text { Instruments, meters, other measuring equipment } \\
\text { and cultural and office equipment }\end{array}$ & IME \\
\hline Arts and crafts products and other manufacturing products & OMF \\
\hline Scrap and waste & WAS \\
\hline Electricity, heat and hot water supply & ELE \\
\hline Gas production and supply & GDT \\
\hline Water production and supply & WTR \\
\hline Construction & $\mathrm{CON}$ \\
\hline Transportation and warehousing & TRP \\
\hline Post & SER \\
\hline Telecommunication and software & SER \\
\hline Wholesale and retail trade & TRD \\
\hline Hotels and restaurants & TRD \\
\hline Finance & SER \\
\hline Real estate & SER \\
\hline Rental and business service & SER \\
\hline Scientific research & SER \\
\hline General technical services & SER \\
\hline Geological prospecting and water conservancy & SER \\
\hline Resident services and other service & SER \\
\hline Education & SER \\
\hline Health service and social welfare & SER \\
\hline Culture, sports and recreation & SER \\
\hline Public administration and other NGOs & SER \\
\hline
\end{tabular}


Table A2: Mapping of energy products in energy balance tables to energy products in input-output tables

\begin{tabular}{ll}
\hline \hline Energy products in energy balance tables & Energy products in input-output tables \\
\hline Raw coal & Coal (COL) \\
Cleaned coal & Coal (COL) \\
Other washed coal & Coal (COL) \\
Briquettes & Coal (COL) \\
Coke & Refined oil and coal products (OIL) \\
Other gas from coal & Fuel gas (OIL) \\
Other coking products & Refined oil and coal products (OIL) \\
Crude oil & Crude oil and gas (CRG) \\
Gasoline & Refined oil and coal products (OIL) \\
Kerosene & Refined oil and coal products (OIL) \\
Diesel & Refined oil and coal products (OIL) \\
Fuel oil & Refined oil and coal products (OIL) \\
LPG & Refined oil and coal products (OIL) \\
Refinery gas & Fuel gas (GDT) \\
Other petroleum products & Refined oil and coal products (OIL) \\
Nature gas & Crude oil and gas (CRG) \\
Heat & Electricity and heat (ELE) \\
Electricity & Electricity and heat (ELE) \\
\hline
\end{tabular}

